
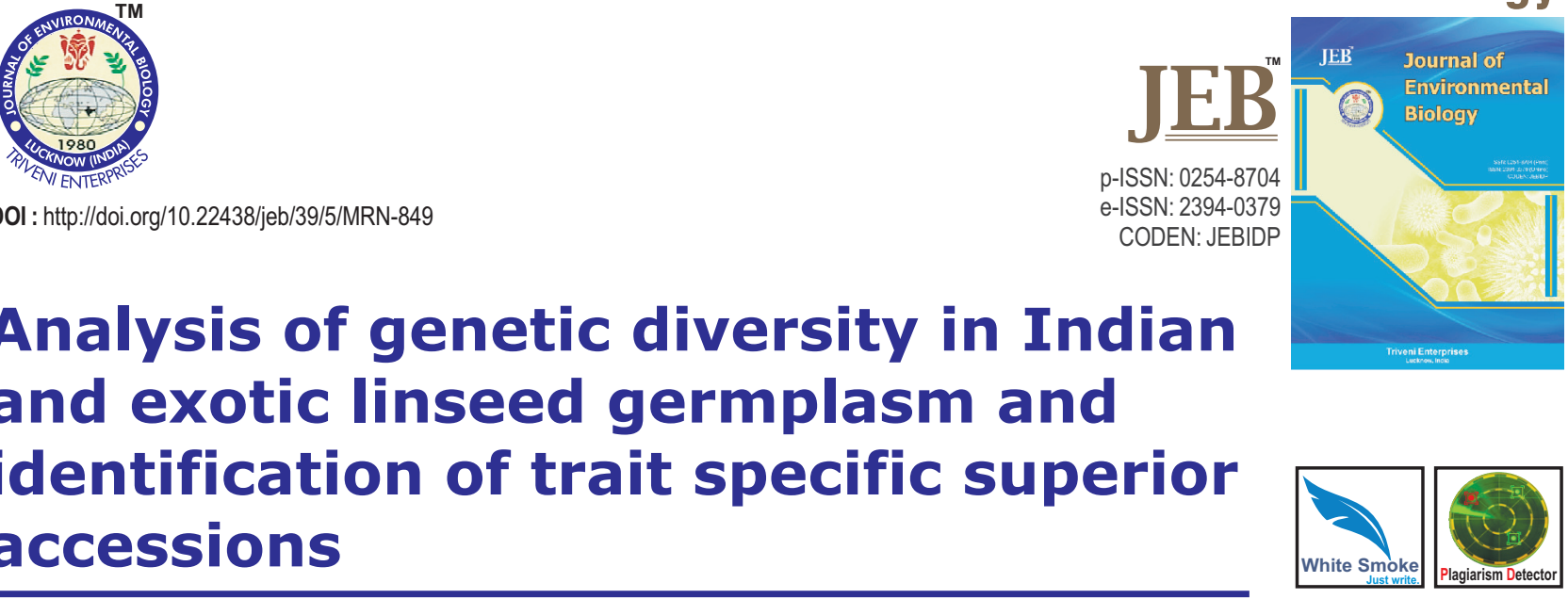

\title{
Analysis of genetic diversity in Indian and exotic linseed germplasm and identification of trait specific superior accessions
}

Authors Info

V. Kaur*, S. Kumar, R. Yadav, D.P. Wankhede, J. Aravind, J. Radhamani, J.C. Rana and A. Kumar

ICAR-National Bureau of Plant Genetic Resources, Pusa Campus, New Delhi-110 012, India

*Corresponding Author Email : Vikender.Kaur@icar.gov.in

Key words

Characterization Genetic diversity Linseed germplasm Promising donors

Publication Info Paper received: 01.02 .2018 Revised received : 21.02.2018 Accepted: 28.02.2018

\section{Abstract}

Aim : Linseed is a multipurpose crop known for oil, fibre, paper, wax and nutraceuticals. Indian subcontinent is a center of origin and domestication for this crop and therefore it is imperative to study the existing genetic diversity among Indian/exotic germplasm accessions.

Methodology : Total 191 accessions of linseed germplasm were evaluated in Augmented Block Design with three check varieties Rashmi, Surabhi, and RLC76 randomized in 7 blocks consisting of 27 accessions each. Descriptive statistics, Principal component analysis (PCA) and Ward's agglomerative hierarchical clustering were done using SAS software. Correlation matrices were generated using $R$.

Results : Wide range of phenotypic expression for important agro-morphological traits was observed in linseed germplasm. PCA identified days to flowering, plant height, thousand seed weight, seed weight and number per boll, seed yield and seed size as the most important traits responsible for variation in the germplasm accessions. Custer analysis grouped the accessions under four major clusters which indicated fair association of genetic diversity and geographical diversity. Few trait specific promising accessions such as IC0096539, IC0096496 (early flowering and maturity), IC0096487, IC0096488 (large boll size), IC0096490 (high oil content and bold seeds), IC0054949, IC0054954 (bold seeds),EC0718827 (tall, large corolla), and EC0718835 (high seed yield/plant) were identified with high estimates of heritability for the mentioned traits. SSR profiling of trait specific accessions was done to develop unique molecular identity.
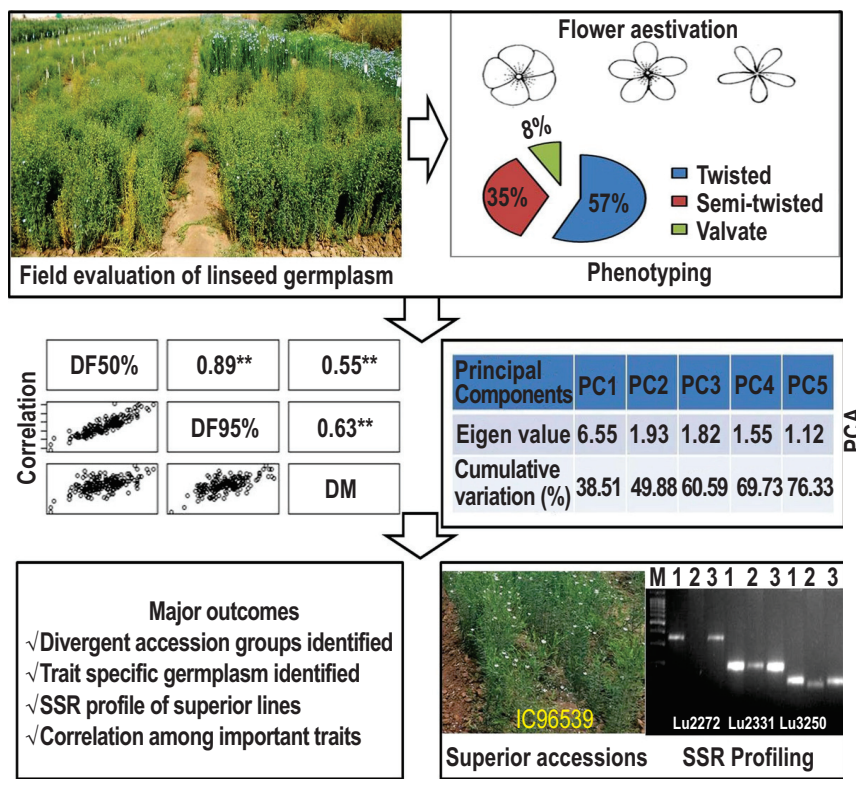

Interpretation : The inter-relationships between the traits suggested that accessions with short flowering and maturity duration, low plant height, large bolls and bold seeds should be given priority in breeding for enhanced yield. Donors for various traits were identified which may be used in future linseed breeding to target yield enhancement and diverse geographical adaptation. 


\section{Introduction}

Linseed (Linum usitatissimum L.) is a self-pollinated annual crop plant with origin either in the Middle East or the Indian regions (Vavilov, 1951). Later it was introduced into New World (The Americas) after vast spread throughout Asia and Europe (Soto-Cerda et al., 2013). Indian subcontinent near the Mediterranean Sea is known to have high biological diversity of genus Linum (Genesar and Morris, 2003; Fu, 2005; Kaur et al., 2017). Differential selection for fibre and oil purpose has led to two distinct morphotypes of linseed-flax type and linseed type, respectively. The taller, less branched fiber flax type is grown in the cool-temperate regions of China, the Russian Federation, Western Europe and shorter, more branched, larger seeded linseed type is grown in continental climate regions of Canada, India, United States of America and Argentina.

The fibre is widely used in linen for textile industry, thread/rope and packaging materials; cigarette paper, currency notes and artwork (Mackiewicz-Talarczyk et al., 2008). The oil extracted from the seeds has unique drying properties having utility in production of paints, inks, varnish and linoleum flooring (Newkirk, 2008; Czemplik et al., 2011). Recently linseed has found application as a functional food owing to high omega-3 alpha linolenic acid content (55-57\%) and seed lignans having anti-cancerous properties (Bassett et al., 2009; Ragupathy et al., 2011). Keeping in view of increasing demand of linseed due to numerous health benefits, there is consistent need to increase genetic potential for seed yield. Presently, the total world production of linseed is approximately 2.65 million tonnes, with Canada (34\%), the Russian Federation (15\%), and China (13\%) being the main producers (FAO, 2017). India is the sixth largest producer in the world with contribution to global linseed area and production $13 \%$ and $5.5 \%$, respectively.

Phenotypic and phenological characterization of a crop species based on standard descriptors is effective for better utilization of germplasm through identification of trait specific superior accessions (Diederichsen and Richards, 2003). From the past, genetic diversity studies in crop plants mostly relied on the evaluation of morphological and agronomic traits (Upadhyaya et al., 2002; Atta-Krah et al., 2004). Earlier genetic variability assessment studies in linseed based on agro-morphological traits were done by Diederichsen, 2001; Diederichsen et al., 2006; Diederichsen and Fu, 2008; Dikshit and Sivaraj, 2015 and Khan et al., 2013. The identification of trait specific promising accessions enhances the overall utilization of genebank collections and is fundamental for breeding and conservation of genetic resources. In India, linseed is primarily cultivated in marginal and sub-marginal, rain-fed soils, with meagre or no application of fertilizers and in utera cultivation by resource poor farmers. Limited competitiveness due to narrow genetic base of released cultivars, cultivation under low input conditions and sensitivity to fungal diseases are the main constraints for low productivity of linseed in India. The present study was therefore, undertaken to analyse the nature and magnitude of genetic variation present in linseed germplasm based on agromorphological, phenological traits and oil content and to identify superior germplasm accessions that can contribute as potential donors for future exploitation in selection and breeding.

\section{Materials and Methods}

Plant materials and field experiment : The plant material used in present study comprised 191 linseed germplasm accessions, of which 159 were indigenous collections (IC) assembled from eight different states of India and 32 were exotic collections (EC) from Australia and Argentina. The crop was raised consecutively for two years during the rabi season 2014-15 and 2015-16 at the experimental farm of the ICAR-National Bureau of Plant Genetic Resources (NBPGR), New Delhi, India. The soil of the field is sandy loam to loamy sand with $\mathrm{pH} 7.5$. The maximum and minimum temperature range was between 25.36 and $9.28^{\circ} \mathrm{C}$ with Relative Humidity ranging from 53.25 to $91.26 \%$ during the crop growth period. Average precipitation of $240 \mathrm{~mm}$ was received. The germplasm was evaluated in Augmented Block Design (Federer, 1956) with three check varieties Rashmi, Surabhi, and RLC76 in 7 blocks. Each block had 27 accessions and three check varieties which were randomized within blocks. Each accession was sown in three rows of $3 \mathrm{~m}$ row length with $30 \times 10 \mathrm{~cm}$ spacing. The trait specific accessions were further validated during the year 2016-17 at two locations.

Phenotyping of agro-morphological and phenological traits : Observations were recorded on 25 traits of which 8 traits viz. growth habit (GH), corolla colour (CC), flower shape (FS), petal aestivation (PA), stamen colour (SC), anther colour (AC), boll dehiscence (BD) and seed coat colour (SCC) were qualitative, while 17 traits viz. days to $50 \%$ flowering (DF $50 \%$ ), days to $95 \%$ flowering (DF 95\%), flower diameter (FD; mm), plant height (PH; $\mathrm{cm}$ ), no. of primary branches (PB), number of bolls per plant (BPP), number of seeds per boll (SPB), seed weight per boll (SWB, $\mathrm{mg}$ ), days to $80 \%$ maturity (DM), boll size (BS; $\mathrm{mm}$ ), boll area $\left(B A ; m^{2}\right)$, seed length $(S L ; m m)$, seed width (SW; $\left.\mathrm{mm}\right)$, seed area $\left(\mathrm{SA} ; \mathrm{mm}^{2}\right)$, seed yield per plant (SPP), 1000-seed weight (TSW; g), and oil content (OC; \%) were quantitative in nature. NBPGR minimal descriptors and descriptor states for linseed were followed for data recording as prescribed by Mahajan et al. (2000). Data were collected during both the years from five plants tagged randomly from the middle of rows of each accession to avoid border effect. Few traits such as GH, DF 50\%, DF 95\%, DM, and SCC were recorded on a plot basis. The Royal Horticultural Society (RHS) color chart was used to determine color. Oil content was determined using petroleum ether as a solvent in Soxhlet extraction system as per AOAC method number 920.58 . Seeds from single plant made one replicate and three replicates were evaluated for oil content estimation. BS, SL, SW, SPB, and SWB were recorded as the average of three random samples of 15 bolls from each of the 5 tagged plants per accession. The boll and seed morphometry was done using scanner based Grain Analysis software (version 1.3). 
Genomic DNA extraction and PCR amplification : Total genomic DNA was extracted using plant genomic DNA isolation kit (Geno Bioscineces). PCR primers for SSR profiling were used as mentioned in Cloutier et al. (2012). PCR amplification were carried out with initial denaturation step at $95^{\circ} \mathrm{C}$ for $5 \mathrm{~min}$ followed by later denaturation of $35 \mathrm{cycles}$ for $30 \mathrm{sec}$ at $95^{\circ} \mathrm{C}$, primer annealing at $52^{\circ} \mathrm{C}$ for $30 \mathrm{sec}$, and extension at $72^{\circ} \mathrm{C}$ for $1 \mathrm{~min}$. Final extension at $72^{\circ} \mathrm{C}$ for $7 \mathrm{~min}$ was followed. The PCR reactions were terminated at $4{ }^{\circ} \mathrm{C}$ and electrophoresedon $3 \%$ metaphor agarose gel (w/v) with ethidium bromide.

Statistical analysis : Statistical parameters viz. mean, range, variances, principal component analysis (PCA) and Ward's agglomerative hierarchical classification (Ward, 1963) were done using SAS (SAS version 9.3, 2009). Homogeneity of variances was tested as per Levene (1960) before undertaking statistical analysis on the basis of adjusted pooled mean values. Phenotypic and genotypic coefficients of variation (PCV and GCV) for each trait were computed as $P C V=\sqrt{ } V_{P} /$ mean $x$ 100, GCV $=\sqrt{ } V_{G} /$ mean $\times 100$ as per (Burton, 1952) and categorized the range as per Sivasubramanian and Madhavamenon (1978). Broad sense heritability was estimated $\mathrm{as} \mathrm{h}^{2}(\mathrm{bs})=\mathrm{V}_{G} / \mathrm{V}_{\mathrm{P}} \times 100$ (Lush, 1940) and it was further classified into low, medium and high as per Robinson (1996). Expected genetic advance as $E G A=k x V_{G} V_{p} \times \sqrt{ } V_{p}$ was calculated as per Johnson et al. (1955). Here the standard value of $k$ is 2.06 assumed at $5 \%$ selection intensity; $V_{G}$ is genotypic variance; and $V_{p}$ is phenotypic variance. Genetic advance was expressed as $\%$ of mean as $\mathrm{GA}(\%)=\mathrm{EGA} /$ mean $\times 100$. In addition, Pearson correlation coefficients were computed at $P_{0.05}$ and $P_{0.01}$ and correlation matrices were generated using $R$.

\section{Results and Discussion}

For qualitative traits : Semi-erect growth habit was observed for $82 \%$ accessions, bushy for $13 \%$ and $5 \%$ were erect type. Flower shape included disk shaped (178 accessions), star shaped (11 accessions) and funnel shaped (2 accessions). A wide range of variation was recorded with respect to corolla color (CC) ranging from blue, white, violet, purple along with varying tonalities, however blue colored flowers were predominant. Earlier the diversity studies in linseed by Hayes and Immer (1942) and Worku et al. (2015) reported red-violet and pink color corolla accessions which are different from our study. Also we did not score yellow and lavender color petals reported from world core collection of linseed by Diederichsen (2007). Petal aestivation was semi-twisted in $71 \%$ accessions, twisted for $25 \%$ and valvate for others. Predominant anther color was cream in $50 \%$ accessions followed by blue $(24 \%)$, yellow $(22 \%)$ and grey $(4 \%)$. Only blue and yellow colored anthers were reported by Flax Council of Canada (1996) and Hayes and Immer (1942), different from the range of anther colors found here, whereas, Diederichsen and Fu (2008) reported three anther colors : white, blue and yellow. Blue stamen color was recorded in $70 \%$ accessions in contrast to white in $30 \%$. Stamen color had a narrower range of color than anthers and petals. Seed coat color varied from different shades of brown to yellow, however medium brown $(96 \%)$ was

Table 1 : Statistical parameters of genetic variability in linseed based on pooled average for two years (2014-15 and 2015-16)

\begin{tabular}{lllllllll}
\hline Traits (n=191) & Range & Mean \pm SE & $\begin{array}{l}\text { Variance } \\
(\mathbf{P})\end{array}$ & $\begin{array}{l}\text { Variance } \\
(\mathbf{G})\end{array}$ & $\begin{array}{l}\text { PCV } \\
(\%)\end{array}$ & $\begin{array}{l}\text { GCV } \\
(\%)\end{array}$ & $\begin{array}{l}\text { Heritability } \\
\text { Genetic advance } \\
\text { as of mean }\end{array}$ \\
\hline DF 50\% & $58-110$ & $86.18 \pm 0.64$ & 53.76 & 49.98 & 8.51 & 8.20 & 92.97 & 16.29 \\
DF 95\% & $77-133$ & $105.20 \pm 0.59$ & 49.34 & 29.12 & 6.68 & 5.13 & 59.02 & 8.12 \\
DM & $97-168$ & $132.48 \pm 0.59$ & 70.08 & 41.62 & 6.32 & 4.87 & 59.39 & 7.73 \\
PB & $5-17$ & $8.93 \pm 0.16$ & 3.62 & 0.79 & 21.31 & 9.95 & 21.82 & 9.58 \\
PH & $30.48-100.82$ & $55.20 \pm 0.80$ & 85.14 & 45.99 & 16.72 & 12.29 & 54.02 & 18.60 \\
FD & $13.00-26.27$ & $17.31 \pm 0.15$ & 5.35 & 1.00 & 13.36 & 5.78 & 18.69 & 5.15 \\
BPP & $36.83-168.55$ & $115.16 \pm 1.70$ & 639.43 & 552.32 & 21.96 & 20.41 & 86.38 & 39.07 \\
BS & $5.39-7.70$ & $6.52 \pm 0.03$ & 0.13 & 0.11 & 5.53 & 5.09 & 84.62 & 9.64 \\
BA & $22.87-46.73$ & $33.67 \pm 0.29$ & 13.63 & 10.63 & 10.96 & 9.68 & 77.99 & 17.62 \\
SPB & $5.17-12.93$ & $8.29 \pm 0.10$ & 1.93 & 1.52 & 16.76 & 14.87 & 78.76 & 27.19 \\
SWB & $23.33-88.47$ & $53.56 \pm 0.79$ & 111.77 & 56.90 & 19.74 & 14.08 & 50.91 & 20.70 \\
SPP & $1.26-16.00$ & $8.28 \pm 0.20$ & 7.37 & 6.16 & 32.79 & 29.98 & 83.58 & 56.45 \\
SL & $3.95-5.98$ & $5.07 \pm 0.03$ & 0.13 & 0.12 & 6.97 & 6.95 & 99.20 & 14.25 \\
SW & $2.35-3.48$ & $2.86 \pm 0.03$ & 0.04 & 0.04 & 6.99 & 6.92 & 98.00 & 14.12 \\
SA & $6.87-15.13$ & $10.83 \pm 0.12$ & 2.06 & 2.05 & 13.25 & 13.22 & 99.56 & 27.18 \\
TSW & $2.05-8.78$ & $6.38 \pm 0.10$ & 1.56 & 1.34 & 19.58 & 18.14 & 85.90 & 34.64 \\
OC & $30.33-42.99$ & $39.05 \pm 0.16$ & 4.49 & 4.43 & 5.43 & 5.39 & 98.66 & 11.03 \\
\hline
\end{tabular}

DF $50 \%$, days to $50 \%$ flowering; DF $95 \%$, days to $95 \%$ flowering; DM, days to maturity; PB, primary branches per plant; PH, plant height; FD, flower diameter; BPP, bolls per plant; BS, boll size; BA, boll area; SPB, seed per boll; SWB, seed weight per boll; SPP, seed yield per plant; SL, seed length; SW, seed width; TSW, thousand seed weight; OC, oil content 
Table 2 : Principal Component analysis (PCA) based on standardized data for 17 quantitative traits of linseed

\begin{tabular}{llllll}
\hline Eigen value & 6.55 & 1.93 & 1.82 & 1.55 & 1.12 \\
\hline $\begin{array}{l}\text { Proportional } \\
\text { variation (\%) }\end{array}$ & 38.51 & 11.37 & 10.71 & 9.14 & 6.61 \\
$\begin{array}{l}\text { Cumulative } \\
\text { variation (\%) }\end{array}$ & 38.51 & 49.88 & 60.59 & 69.73 & 76.33 \\
Traits & PC1 & PC2 & PC3 & PC4 & PC5 \\
DF 50\% & -0.32 & 0.08 & 0.12 & 0.19 & 0.27 \\
DF 95\% & -0.32 & 0.08 & 0.21 & 0.19 & 0.25 \\
DM & -0.17 & -0.07 & 0.36 & 0.40 & 0.31 \\
PB & -0.10 & 0.05 & -0.43 & 0.33 & 0.05 \\
PH & -0.12 & $\mathbf{0 . 4 2}$ & $\mathbf{0 . 3 3}$ & -0.26 & 0.04 \\
FD & -0.13 & $\mathbf{0 . 4 5}$ & 0.25 & -0.04 & 0.04 \\
BPP & 0.01 & $\mathbf{0 . 3 9}$ & -0.28 & 0.39 & 0.14 \\
BS & $\mathbf{0 . 2 6}$ & 0.16 & 0.27 & 0.30 & -0.41 \\
BA & 0.26 & 0.16 & 0.27 & 0.30 & -0.41 \\
SPB & $\mathbf{0 . 2 7}$ & 0.22 & -0.14 & -0.14 & -0.21 \\
SWB & 0.14 & $\mathbf{0 . 2 6}$ & -0.13 & -0.29 & -0.03 \\
SPP & 0.03 & $\mathbf{0 . 4 8}$ & -0.33 & 0.02 & 0.12 \\
SL & 0.35 & 0.03 & 0.07 & -0.07 & 0.34 \\
SW & $\mathbf{0 . 3 5}$ & 0.01 & 0.06 & -0.02 & 0.32 \\
SA & $\mathbf{0 . 3 6}$ & 0.01 & 0.07 & -0.03 & 0.33 \\
TSW & $\mathbf{0 . 3 2}$ & 0.19 & 0.04 & -0.01 & 0.13 \\
OC & 0.16 & -0.04 & -0.24 & 0.37 & -0.09 \\
\hline
\end{tabular}

Bold values indicate the highest values among all five PCs for each trait which represents relative contribution of respective $\mathrm{PC}$ in explaining the variation. Abbreviations: DF 50\%, days to $50 \%$ flowering; DF $95 \%$, days to $95 \%$ flowering; DM, days to maturity; PB, primary branches per plant; $\mathrm{PH}$, plant height; FD, flower diameter; BPP, bolls per plant; BS, boll size; BA, boll area; SPB, seed per boll; SWB, seed weight per boll; SPP, seed yield per plant; SL, seed length; SW, seed width; TSW, thousand seed weight; $\mathrm{OC}$, oil content

predominant. Thus in the present study the most common type of linseed germplasm accessions were characterized by disk shaped flowers with blue corolla, semi-twisted aestivation, indehiscent capsules and brown seed coat color.

General statistical analysis showed wide range of phenotypic expression for important agro-morphological traits such as PH (30.48-100.82 cm), FD (13.00-26.27 mm), PB (5-17), BPP (36.83-168.55), SWB (23.33-88.47 mg), SPP (1.26-16.00 $\mathrm{g}$ ), and TSW (2.05-8.78 g) (Table 1). The mean DF $50 \%$ were 86 , but it ranged from 58 for accession IC0096539 to 110 days for accession EC0718844. Accession IC0096539 having white colored funnel shaped flowers showed early maturity in 102 days whereas early maturing variety Kartika (RLC76) used as check took 118 days for maturation. Another accession IC0096496 showed earliness/short duration with 60 days for $50 \%$ flowering and 97 days to attain maturity. Average boll count per plant was 115 while range was 36.83-168.55 for IC0054968 and IC0426935. EC0718845 and IC0267682 had maximum number of seeds/boll (12.93) while IC0054968 had minimum (5.17). TSW, an important yield character, varied extensively from $2.05 \mathrm{~g}$ to $8.78 \mathrm{~g}$ with an average of $6.38 \mathrm{~g}$. It was more than $8 \mathrm{~g}$ for
IC0096490, IC0096488, IC0096489 and IC0096543 which are landraces of Maharashtra. Accessions IC0054949, IC0054954 and IC0054960 had maximum SL (5.96 mm), SW (3.48 mm) and $\mathrm{SA}\left(15.13 \mathrm{~mm}^{2}\right)$, thus were bold seeded. The wide range of variation observed in this study also corroborated earlier diversity assessment studies in linseed by Akbar et al. (2003) for BPP, PH and TSW; Nagaraja et al. (2009) for SPP; Sivaraj et al. (2012) for PH, SPP and TSW; Tadesse et al. (2010) and Adugna and Labuschagne (2002) for SPP, TSW, DF $50 \%$ and DM. For OC, the range was 30.33-42.99\% with accessions IC0096490 and IC0268345 having $42.9 \%$ and $42.7 \%$ oil content, respectively, which is significantly higher than check varieties RLC76 (38.16\%) and Rashmi (37.25\%). Diederichsen and Fu (2008) observed a wide range of variation in oil content from 31.4 to $45.7 \%$ with mean of $38.3 \%$ in a large collection of 2934 accessions of linseed from 72 countries. Our results are in agreement with Diederichsen and Fu (2008) for mean oil content, however we observed comparatively narrow range of variation in oil content due to small number of accessions under study. Recent studies by Nizar and Mulani (2015), Dikshit and Sivaraj (2015) indicated good variability for agro-morphological traits and oil content in Indian linseed germplasm.

PCV and GCV were high for SPP, BPP, TSW, SWB, SPB and $\mathrm{PH}$ and low for rest of the traits. The heritability was found high (>78\%) for SA, SL, SW, OC, DF 50\%, BPP, TSW, BS, SPP, SPB and BA, medium for DF 95\%, DM, PH and SWB while traits FD and PB were having low heritability $(<30 \%)$. Small difference in estimates of GCV in relation to PCV indicates that observed variation is mainly due to genetic factors while larger difference indicates role of environment. The mean GA (\%) was high (>20) for SPP, BPP, TSW, SPB, SA, SWB and low or medium for rest of the traits. In studied linseed germplasm, SA, SL, SW, OC, DF $50 \%$, BPP, TSW, and BS showed high heritability in broad sense coupled with high estimates of genetic advance and are predominantly under additive type of gene action. Accessions such as IC0096496, IC0096539, IC0096487, IC0096488, IC0096489, IC00426935, IC0054949, IC0054954, IC0054960, IC0096490, IC0096543 and IC0268345 showed high values for these traits and can be subjected for seed and oil yield gain through simple selection based on phenotypic performance. These characters showed $>85 \%$ heritability and may be useful for exploiting additive gene action to produce widely adapted genotypes in linseed breeding as also suggested by Kumar et al. (2012); Mirza et al. (2011) and Akbar et al. (2003). Our results are also in congruence with Ahmad et al. (2014) in linseed and Khan et al. (2007) in sesame who reported high heritability estimation for days to flower initiation, days to maturity, 100 seed weight and seed yield. On the other hand, parameters such as PB, FD, DF 95\% and DM showed low estimates of heritability and genetic advance which means that effect of environmental conditions is more on these traits as compared to other traits. These traits are under the influence of non-additive gene interaction and needed to be improved by hybridization.

The matrix developed for correlations among important traits along with correlation coefficients showed positive 


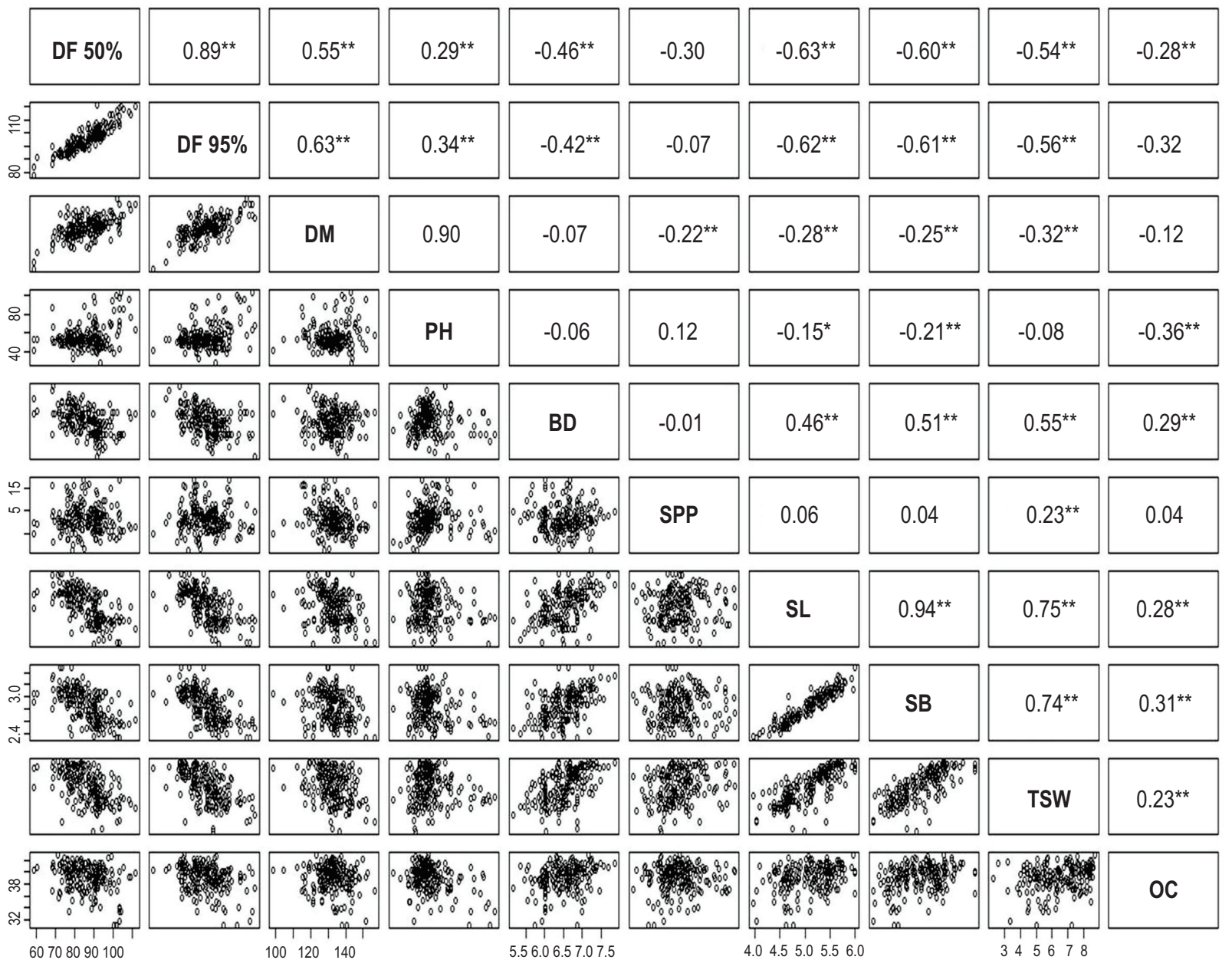

Fig. 1 : The pairwise correlations of different morpho-phenological and agronomic traits for linseed germplasm accessions. The upper-right panels show the numerical values of the correlations (rounded to two decimal places). The ${ }^{*}$ and ${ }^{* *}$ indicate correlation significance at $P_{0.05}$ and $P_{0.01}$ levels of probability, respectively. The lower-left panels show the scatter plots. Abbreviations: DF $50 \%$, days to $50 \%$ flowering; DF $95 \%$, days to $95 \%$ flowering; DM, days to maturity; PH, plant height; BS, boll size; SPP, seed yield per plant; SL, seed length; SW, seed width; TSW, thousand seed weight; OC, oil content

correlation of TSW with SL, SB, SPP, BS and OC and negative correlation with DF 50\%, DF $95 \%$ and DM (Fig. 1). Significant positive correlation of boll and seed size with each other and with TSW and OC were found which suggest that selection for bold seeds and larger bolls may favor improvement in seed yield and oil content. Dikshit and Sivaraj (2015) had also reported significantly positive correlation between seed weight and oil content while negative association between DF $50 \%$ and TSW. As discussed earlier, most of the indigenous accessions under study were semi-erect or bushy type which are low in height and are oil type in nature is also evident from the negative association of $\mathrm{PH}$ and $\mathrm{OC}$. Similar phenotypic correlations among yield-related traits and other agro-morphological traits have been reported in linseed (Adugna and Labuschagne, 2004), soybean (Panthee et al., 2007), rapeseed (Honsdorf et al., 2010) and maize (Peng et al., 2011). The inter-relationships between the traits suggested that further yield improvement could come from the breeding of an early flowering, short duration, dwarf linseed plant producing bold seeds.

PCA is useful for identification of determinants of quantitative trait variability when a large number of accessions are to be accessed for several characters of morphological and agronomic importance. First five PCs having Eigen value $>1.0$ contributed $76.33 \%$ of the total multivariate variation present in linseed germplasm, $38.51 \%$ of which was accounted for in PC1, and $11.37 \%$ in PC2 (Table 2). Both PC1 and PC2 together explained about $50 \%$ of total variation through traits such as duration of flowering, flower and seed size, TSW and PH. Consequently, the most diverse accessions could be selected on the basis of these two PCs. Worku et al. (2015) studied diversity analysis in Ethiopian linseed and reported results similar to our study and thus confirmed the independence of some traits. PC3, PC4 and PC5 explained 10.71, 9.14 and 


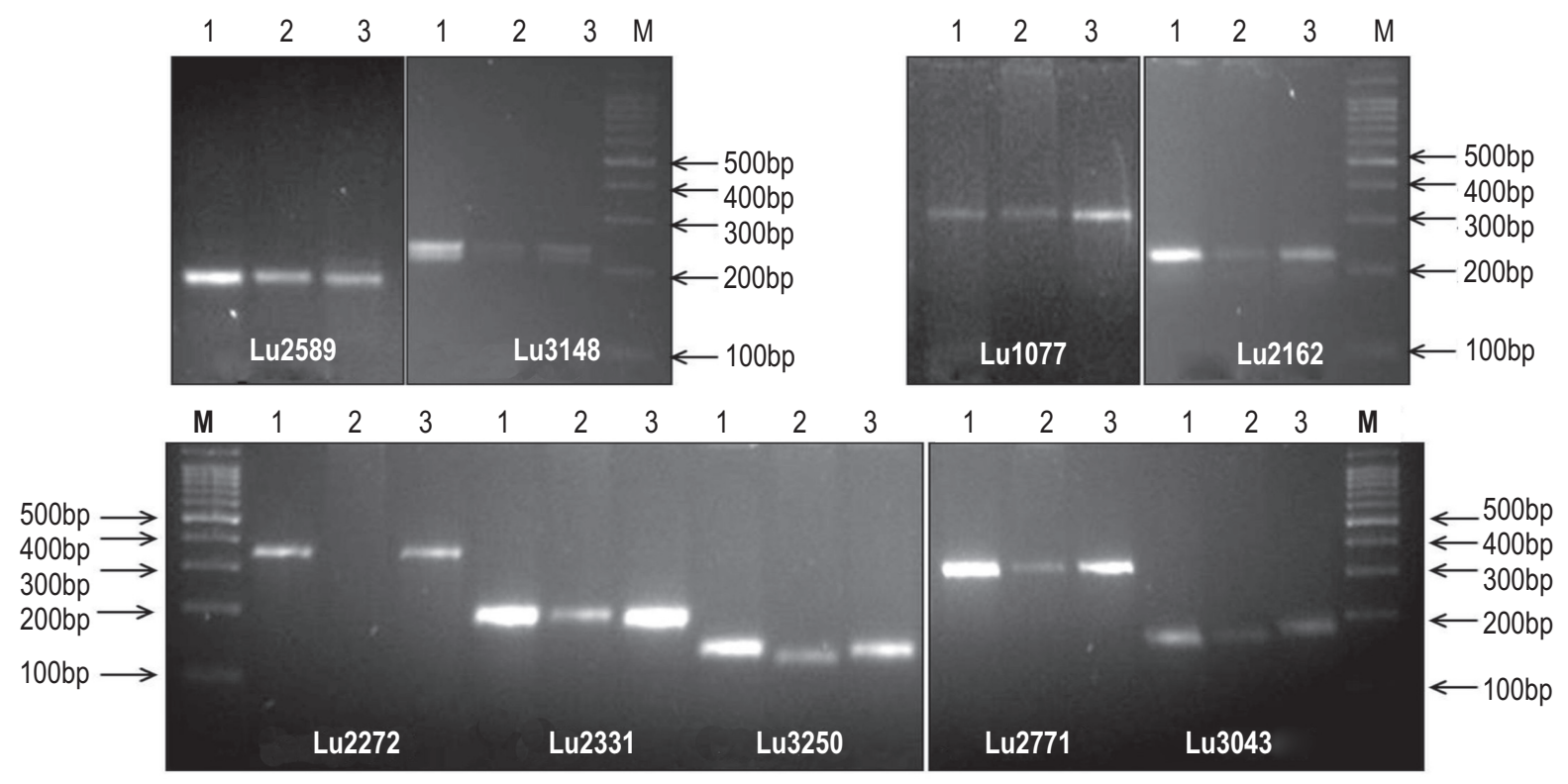

1-Kota Barani, 2-IC0096496, 3-IC0096539

Fig. 2 : Profiling of trait specific germplasm accessions using SSR markers. Lane 1, 2 and 3 indicate reference variety Kota Barani, IC0096496 and IC0096539, respectively. Names of SSR markers have been indicated at the bottom of each three lanes. M is the 100 bp molecular weight size standard (Geno biosciences)

$6.61 \%$ variation, respectively and showed greater weightage for DM, PB, OC, BS and BA.

Cluster analysis groups large number of accessions into few number of homogenous clusters which in turn facilitates the selection of diverse accessions. The number of accessions fallen under cluster III were highest (92), followed by cluster I (56), cluster II (31) and cluster IV (15) as shown in Table 3. The mean values of accessions grouped into each cluster showed that cluster IV had accessions which were taller, late flowering and maturing, but with less oil content. Cluster I grouped accessions with more primary branches, boll count and seed yield per plant. Cluster III mainly comprised of landraces of Maharashtra with early flowering and maturing trait coupled with bold seeds and high TSW. The diversity in the present material is also supported by appreciable amount of variation among cluster means for different traits. The maximum differences were observed between accessions under cluster III and IV indicating genetic distance among them due to different genetic constitutions. Hence, divergent parents selected from these clusters can be utilized for obtaining good segregants and yield improvement in linseed. Paul et al. (2016) grouped linseed genotypes in 8 clusters and suggested intercrossing of genotypes from divergent clusters for yield enhancement. Cluster IV was constituted by exotic accessions only while majority of the accessions from Maharashtra grouped under cluster III. The accessions from Bihar, MP, Jharkhand and UP grouped under cluster I, which also had a sub-group of few exotic accessions apart from cluster IV. Thus cluster analysis showed fair association of genetic diversity with geographical diversity. However our clustering pattern do not corroborate the studies of Adugna and Labuschagne (2004), Nizar and Mulani (2015) and Dikshit and Sivaraj (2015) where
Table 3 : Means of quantitative variables in different clusters of linseed germplasm accessions

\begin{tabular}{lllll}
\hline Cluster variables & C I & C II & C III & C IV \\
\hline DF 50\% & 91.25 & 89.00 & 79.14 & 102.98 \\
DF 95\% & 110.12 & 107.60 & 99.30 & 122.82 \\
DM & 132.55 & 132.50 & 130.83 & 143.11 \\
PB & 10.54 & 8.18 & 8.38 & 7.86 \\
PH & 53.75 & 53.51 & 52.35 & 81.63 \\
FD & 17.34 & 17.66 & 16.46 & 20.66 \\
BA & 30.54 & 29.61 & 37.04 & 32.59 \\
BS & 6.22 & 6.13 & 6.85 & 6.42 \\
BPP & 121.50 & 103.76 & 115.39 & 99.52 \\
SPB & 9.72 & 8.13 & 7.30 & 9.60 \\
SPP & 9.02 & 7.25 & 8.45 & 6.27 \\
SWB & 53.61 & 50.67 & 56.64 & 45.86 \\
SL & 4.63 & 5.12 & 5.42 & 4.50 \\
SW & 2.62 & 2.88 & 3.05 & 2.55 \\
SA & 9.01 & 11.00 & 12.26 & 8.51 \\
TSW & 5.36 & 5.68 & 7.55 & 4.98 \\
OC & 38.77 & 39.11 & 39.68 & 35.80 \\
No. of accessions & 56 & 31 & 92 & 15 \\
\hline
\end{tabular}

DF $50 \%$, days to $50 \%$ flowering; DF $95 \%$, days to $95 \%$ flowering; DM, days to maturity; PB, primary branches per plant; PH, plant height; FD, flower diameter; BPP, bolls per plant; BS, boll size; BA, boll area; SPB, seed per boll; SWB, seed weight per boll; SPP, seed yield per plant; SL, seed length; SW, seed width; TSW, thousand seed weight; OC, oil content

linseed germplasm lines from diverse geographical regions fell apart in the cluster analysis which may happen due to similar 
genetic constitution of material under study or due to free exchange over the boundaries.

The present study also helped identify trait specific superior accessions, which may be included in linseed breeding program. White flowered accession IC0096539 was identified as early flowering (58 days for DF $50 \%$ ) and early maturing (102 days for DM) which is significantly earlier than the early maturing variety, Kartika under Delhi climatic conditions. A few accessions were found promising for more than one trait such as IC0096488 for BS, SWB and TSW; IC0096490 for TSW, OC; IC0096489 for BS, SL, SW and TSW. Non-native cultivars showed better performance for PH and FD (EC0718827), SPP (EC0718835, EC0414778), and SPW (EC0718845), however, these were late maturing, tall and prone to lodging. In India, linseed is a low yielding crop which is grown on marginal land under low input conditions, hence above mentioned accessions may play a pivotal role in development of high yielding cultivars suited to diverse agro-climatic conditions.

In order to develop unique identity of trait specific germplasm SSR profiling of early flowering and maturing accessionsIC0096539 and IC0096496 was done using genetically mapped SSR markers (Cloutier et al., 2012). Nine SSR primer pairs were screened for the identified accessions along with reference variety, Kota barani. As shown in Fig. 2, SSR markers, Lu2589, Lu1077, Lu3250 and Lu3043 together could easily distinguish IC0096539 and IC0096496 among each other and also from the reference variety. SSR markers have routinely been used for DNA fingerprinting of superior genotypes and diversity studies (Bajpai et al., 2016; Kumar etal., 2016).

In conclusion, present study identified DF $50 \%, \mathrm{PH}, \mathrm{TSW}$, SWB, SPB, SPP, SL and SB as the most important traits responsible for variation in linseed germplasm. Correlation matrix suggested that early maturity, short height and large seed size should be given emphasis in breeding programs for further enhancement of seed and oil yield. Trait specific linseed accessions identified such as IC0096496, IC0096539, IC0096487, IC0096488, IC0096489, IC00426935, IC0054949, IC0054954, IC0054960, IC0096490, IC0096543, IC0268345, EC0718827 and EC0718835 had high heritability for economically important traits such as duration of flowering, bold seeds, large bolls, high thousand seed weight and oil content. These accessions can be utilized in linseed breeding to gain yield and to produce widely adapted genotypes for the various agro-ecological zones.

\section{Acknowledgments}

Authors acknowledge use of research facilities available at ICAR-NBPGR and Mr. B. L. Meena, ACTO for assistance in field experiments. Authors thank Dr. Nachiket Kotwaliwale, Principal Scientist, ICAR-CIAE, Bhopal, MP, India for extending help in recording data for seed and boll morphometry.

\section{References}

Adugna, W. and M.T. Labuschagne: Genotype-environment interactions and phenotypic stability analyses of linseed in Ethiopia. Plant Breed., 121, 66-71 (2002).

Adugna, W. and M.T. Labuschagne: Diversity analysis in Ethiopian and some exotic collections of linseed. South African J. Plant Soil., 21, 53-58 (2004).

Ahmad, R., D. Ibrar, D.M. Mirza, Y. Mahmood, T. Khan, M.S. Iqbal and M. Ahmad: Genetic variability, heritability and genetic advance in some genotypes of linseed (Linum usitatissimum L.). J. Agric. Res., 52, 43 (2014).

Akbar, M., T. Mahmood, M. Anwar, M. Ali, M. Shafiq and J. Salim: Linseed improvement through genetic variability, correlation and path coefficient analysis. Int. J. Agri. Biol., 5, 303-305 (2003).

Atta-Krah, K., R. Kindt, J.N. Skilton and W. Amaral: Managing biological and genetic diversity in tropical agroforestry. Agroforest. Syst., 61, 183-194 (2004).

Bajpai, A., M. Muthukumar, I. Ahmad, K.V. Ravishankar, V.A. Parthasarthy, Bhuwon Sthapit, Ramanatha Rao, J.P. Verma and S. Rajan: Molecular and morphological diversity in locally grown noncommercial (heirloom) mango varieties of North India. J. Environ. Biol., 37, 221-228 (2016).

Bassett, C.M., D. Rodriguez-Leyva and G.N. Pierce: Experimental and clinical research findings on the cardiovascular benefits of consuming flaxseed. Appl. Physiol. Nutr. Metab., 34, 965-74 (2009).

Burton, G.W.: Quantitative inheritance in grasses. Proc. Int. Grassl. Cong., 1, 277-283 (1952).

Cloutier, S., R. Ragupathy, E. Miranda, N. Radovanovic, E. Reimer, A. Walichnowski, K. Ward, G. Rowland, S. Duguid and M. Banik: Integrated consensus genetic and physical maps of flax (Linum usitatissimum L.). Theor. Appl. Genet., 125, 1783-95 (2012).

Czemplik, M., A. Boba, K. Kostyn., A. Kulma, A. Mituła, M. Sztajnert, M. Wróbel Kwiatkowska, M. Żuk, J. Jan Szopa and SkórkowskaTelichowska K: Flax engineering for biomedical application. In: Biomedical Engineering, Trends, Research and Technologies (Eds.: M.A. Komorowska and S. Olsztynska-Janus). InTech, Rijeka, Croatia, pp. 407-434 (2011).

Diederichsen, A. and K. Richards: Cultivated flax and the genus Linum L: Taxonomy and germplasm conservation. In: Flax: The genus Linum (Eds. A.D. Muir and N.D. Westcott) CRC Press, London, pp. 22-54 (2003).

Diederichsen, A. and Y.B. Fu: Flax genetic diversity as the raw material for future success. Int. Conf. Flax Other Bast Plants, ID 51, 27- 280 (2008).

Diederichsen, A., T.A. Rozhmina, A.A. Zhuchenko and K.W. Richards: Screening for broad adaptation in 96 flax (Linum usitatissimum L.) accessions under dry and warm conditions in Canada and Russia. Plant Genet. Resour. Newsl., 146, 9-16 (2006).

Diederichsen, A.: Comparison of genetic diversity of flax (Linum usitatissimum L.) between Canadian cultivars and a world collection. Plant Breed.,120, 360-362 (2001).

Diederichsen, A.: Ex-situ collections of cultivated flax (Linum usitatissimum) and other species of the genus Linum. Genet. Resour. Crop Evol., 54, 661-678 (2007).

Dikshit, N. and N. Sivaraj: Analysis of agro-morphological diversity and oil content in Indian linseed germplasm. Grasas Aceites, 66, e060 (2015).

FAO: Food and agricultural commodities production. http:// faostat.fao. 
org/ site/339/ default. aspx (2017).

Federer, W.T.: Augmented (or hoonuiaku) designs. Hawaii Plant Record, 55, 191-208 (1956).

Flax Council of Canada: Growing flax. Production, management and diagnostic guide. The flax Council of Canada, Winnipeg, MB, Canada, pp. 1-56 (1996).

Fu, Y.B.: Geographic patterns of RAPD variation in cultivated flax. Crop Sci., 45, 1084-1091 (2005).

Genser, A.D. and N.D. Morris : History of cultivation and uses of flaxseed. In: Flax- The genus Linum (Eds. A.D. Muir and N.D. Westcott), Taylor and Francis, London (2003).

Hayes, H.K. and F.R. Immer: Methods of Plant Breeding. McGraw-Hill, New York (1942).

Honsdorf, N., H.C. Becker and W. Ecke: Association mapping for phenological, morphological, and quality traits in canola quality winter rapeseed (Brassica napus L.). Genome, 53, 899-907 (2010).

Johnson, H.W., H.F. Robinson and R.E. Comstock: Estimates of genetic and environmental variability in Soybean. Agron. J., 47, 314-318 (1955).

Kaur, V., R. Yadav and D.P. Wankhede: Linseed (Linum usitatissimum L.) genetic resources for climate change intervention and its future breeding. J. Appl. Nat Sci., 9, 1112-1118 (2017).

Khan, M.A., M.Y. Mirza., M. Akmal., N. Ali and I. Khan: Genetic parameters and their implications for yield improvement in sesame. Sarhad J. Agric., 23, 623-627 (2007).

Khan, M.A., M.Y. Mirza., M. Amjad, N. Nawaz., M.S. Nawaz and D. Baig: Assessment of genetic diversity in germplasm of linseed (Linum usitatissimum) Pak. J. Agric. Res., 26, 178-184 (2013).

Kumar, S., S.A. Kerkhi, L.K. Gangwar, P. Chand and M. Kumar: Improvement in the genetic architecture through study of variability, heritability and genetic advance in linseed crop (Linum usitatissimum L.). Int. J. Res. Eng, IT Soc. Sci., 2, 58-65(2012).

Kumar, S., V. Kumar, P. Kumari, Kirti, A.K. Singh and R. Singh: DNA fingerprinting and genetic diversity studies in wheat genotypes using SSR markers. J. Environ. Biol., 37, 319-326 (2016).

Levene, H.: Robust testes for equality of variances. In: Contributions to probability and statistics (Ed.: I. Olkin). Stanford University Press, PaloAlto, California, pp. 278-292 (1960).

Lush, J.L.: Intrusive collection of regression of offspring on dams as a method of estimating heritability of characters. Proc. Am. Soc. Anim. Prod., 33, 293-301 (1940).

Mackiewicz-Talarczyk, M., J. Barriga-Bedoya, J. Mankowski and I. Pniewska: Global flax market situation. ID\#97, International Conference on Flax and Other Bast Plants (ISBN \#978-09809664-0-4), pp. 408-412 (2008).

Mahajan, R.K., R.L. Sapra, U. Srivastava, M. Singh and G.D. Sharma: Minimal descriptors (for characterization and evaluation) of agrihorticultural crops (Part I). National Bureau of Plant Genetic Resources, New Delhi (2000).

Mirza, M.Y., M.A. Khan, M. Akmal, A.S. Mohmand, M.S. Nawaz, N. Nawaz and N. Ullah: Estimation of genetic parameters to formulate selection strategy for increased yield in linseed. Pak. J. Agric. Res., 24, 19-24 (2011).
Nagaraja, T.E., K.R. Ajit and B.S. Golasangi: Genetic variability, correlation and path analysis in linseed. J. Maharashtra Agri. Univ., 34, 282-285 (2009).

Newkirk, R.: Flax Feed Industry Guide. Flax Canada, 2015 (2008).

Nizar, M.A. and R.M. Mulani: Genetic diversity in indigenous and exotic linseed germplasm (Linum usitatissimum L.) Electron. J. Plant Breed., 6, 848-854 (2015).

Panthee, D.R., V.R. Pantalone, A.M. Saxton, D.R. West and C.E. Sams: Quantitative trait loci for agronomic traits in soybean. Plant Breed.,126, 51-57 (2007).

Paul, S., A. Kumari and D. Sharma: Estimation of phenotypic divergence in linseed (Linum usitatissimum L.) for yield related traits under changed climate in mid-hills of North-West Himalayas. Bangladesh J. Bot., 45, 1163-1171 (2016).

Peng, B., Y. Li, Y. Wang, C. Liu, Z. Liu, W. Tan, Y. Zhang, D. Wang, Y. Shi, B. Sun, Y. Song, T. Wang and Y. Li: QTL analysis for yield components and kernel-related traits in maize across multienvironments. Theor. Appl. Genet., 122, 1305-1320(2011).

Ragupathy, R., R. Rathinavelu and S. Cloutier: Physical mapping and BAC-end sequence analysis provide initial insights into the flax (Linum usitatissimum L.) genome. B.M.C. Genomics, 12, 217 (2011).

Robinson, H.F.: Quantitative genetics in relation to breeding of the centennial of Mendalism. Ind. J. Genet., 26, 171-187 (1966).

SAS Institute: Statistical analysis software system, Version 9.3. SAS Institute, Cary, NC, USA(2009).

Sivaraj, N., N. Sunil, S.R. Pandravada, V. Kamala, B. Abraham, V. Kumar, B.V.S.K. Rao, R.B.N. Prasad and K.S. Varaprasad: Variability in linseed (Linum usitatissimum) germplasm collections from peninsular India with special reference to seed traits and fatty acid composition. Indian J. Agri. Sci., 82, 102-105 (2012).

Sivasubramanian, S. and P. Madhavamenon: Genotypic and phenotypic variability in rice. Madras Agric. J., 60, 1093-1096 (1978).

Soto-Cerda, B.J., A. Diederichsen, R. Ragupathy and S. Cloutier: Genetic characterization of a core collection of flax (Linum usitatissimum L.) suitable for association mapping studies and evidence of divergent selection between fibre and linseed types. B.M.C. Plant Biol.,13, 78 (2013).

Tadesse, T., A. Parven, H. Singh and B. Weyessa: Estimates of variability and heritability in linseed germplasm. Int. J. Sustain. Crop Prod., 5, 8-16 (2010).

Upadhyaya, H.D., P.J. Bramel, R. Ortiz and S. Singh: Geographical pattern of diversity for morphological and agronomic traits in the groundnut germplasm collection. Euphytica, 128, 91-204 (2002).

Vavilov, N.I.: The origin, variation, immunity and breeding of cultivated plants. Chronica Botanica, 13, 1-366 (1951).

Ward, J.H.: Hierarchical grouping to optimize an objective function. J. Am. Stat. Assoc., 58, 236-244 (1963).

Worku, N, J.S. Heslop-Harrison and W. Adugna: Diversity in 198 Ethiopian linseed (Linum usitatissimum) accessions based on morphological characterization and seed oil characters. Genet. Resour. Crop Evol., 62, 1037-1053 (2015). 